Check for updates

Cite this: RSC Adv., 2018, 8, 18828

Received 3rd April 2018

Accepted 17th May 2018

DOI: $10.1039 / c 8 r a 02863 j$

rsc.li/rsc-advances

\section{Improving microalgal growth by strengthening the flashing light effect simulated with computational fluid dynamics in a panel bioreactor with horizontal baffles $\dagger$}

\begin{abstract}
Qing Ye, Jun Cheng, (D * Zongbo Yang, Weijuan Yang, Junhu Zhou and Kefa Cen
Biological $\mathrm{CO}_{2}$ elimination by photosynthetic microalgae is a sustainable way to mitigate $\mathrm{CO}_{2}$ from flue gas and other sources. Computational fluid dynamics was used to simulate algal cell movement with an enhanced flashing light effect in a novel panel bioreactor with horizontal baffles. Calculation results showed that the light/dark (L/D) cycle period decreased by $17.5 \%$ from $17.1 \mathrm{~s}$ to $14.1 \mathrm{~s}$ and that the horizontal fluid velocity increased by $95 \%$ while horizontal baffles were used under a 0.02 vvm air aeration rate and a microalgal concentration of $0.85 \mathrm{~g} \mathrm{~L}^{-1}$. The probability of the L/D cycle period within $5-10 \mathrm{~s}$ increased from $27.9 \%$ to $43.6 \%$, indicating a $56 \%$ increase when horizontal baffles existed. It was proved by experiments that the mass-transfer coefficient increased by $31 \%$ and the mixing time decreased by $13 \%$ under a $0.06 \mathrm{vvm}$ air aeration rate when horizontal baffles were used, and the algal biomass yield increased by $\sim 51 \%$ along with the decrease in the L/D cycle period when horizontal baffles were used.
\end{abstract}

\section{Introduction}

$\mathrm{CO}_{2}$ is a greenhouse gas that mainly causes global warming and contributes to the formation of hostile environments. $\mathrm{CO}_{2}$ biological elimination by photosynthetic microalgae is a crucial way to mitigate $\mathrm{CO}_{2}$ from different sources, including the atmosphere and industrial exhaust gases, especially flue gas of coal-fired power plants. ${ }^{1}$ Lipid production from microalgae was also been optimized for new energy developments. ${ }^{2,3}$ Microalgae cultivation is vital in the utilization of microalgal biomass. Various types of bioreactor have been extensively utilized for algal culture, such as a raceway pond, flat panel bioreactors, and tubular reactors. Particularly, flat panel bioreactors have many advantages, such as a large illuminated surface, suitability for outdoor cultivation, good productivity, and being easy to clean. ${ }^{4}$ An appropriate mixed multiphase flow state in bioreactors is pivotal to supply $\mathrm{CO}_{2}$ efficiently, eliminate produced oxygen, provide alternate periods of light/dark (L/D), equably distribute nutrients, and avoid cell sedimentation. ${ }^{5}$ The influence of L/D cycles with different light intensities on the growth of microalgae has been researched..$^{6-9}$ The vivid characterization of flow field in photobioreactors via experiment is difficult and costly to achieve. ${ }^{10}$ Developments of computational fluid dynamics

State Key Laboratory of Clean Energy Utilization, Zhejiang University, Hangzhou 310027, China. E-mail: juncheng@zju.edu.cn; Fax: +86 571 87951616; Tel: +86 571 87952889

$\dagger$ Electronic supplementary information (ESI) available. See DOI: $10.1039 / \mathrm{c} 8 \mathrm{ra02863j}$
(CFD) and the availability of more powerful computers have paved the way for the modeling and designing of a bioreactor. ${ }^{11,12}$ Soman et al. (2015) designed a bioreactor that combined flat plate bioreactors and airlift, and then further studied the superior liquid circulation properties of the bioreactor using CFD. ${ }^{13}$ It was proved that the design had a better surface to volume ratio and hydrodynamic properties. Kommareddy et al. (2017) further simulated the algal growth and hydrodynamic properties in the same bioreactors. ${ }^{14}$ Massart et al. (2014) established and validated a CFD hydrodynamic model for a flat-panel airlift bioreactor. ${ }^{15}$ In this respect, experimental water flow rates and the liquid circulation in the riser of the reactor were compared with the CFD solution results. However, these cases were simple combinations of airlift and flat plate bioreactors. So the problems of airlift bioreactors still existed in these design, such as low turbulent kinetic energy and low horizontal velocity in the downcomer. ${ }^{16}$ Moreover, microalgal cells movement and L/D cycle in the bioreactor were not investigated. New structure that can overcome the drawbacks of usual airlift flat panel photobioreactors should be designed and investigated.

The $\mathrm{CO}_{2}$ mass transfer performance of an airlift flat-plate bioreactor with flat baffle and waved baffle was studied by Chen et al. (2016) ${ }^{17}$ through the numerical and experimental methods. The results showed that the downcomer-to-riser cross-sectional area ratio played a major role on the mass transfer behavior of flat-plate airlift bioreactor. However, this research only studied the gas mass transfer in the reactor. The 
algal movement and L/D cycle of microalgal cells were not investigated. Moreover, algal cultivation validation was not performed. The flat-plate PBRs equipped with internal mixers was developed and further optimized its structure parameters using CFD by Huang et al. (2015). ${ }^{18}$ The maximum cell concentration and biomass productivity were $11.3 \%$ and $22.2 \%$ higher than those in the archetype. However, microalgal cells movement and L/D cycle in the bioreactor were not investigated. Novel baffles named HTTP baffles that produce vortices to improve the fluid velocity between light and dark areas in a flatpanel bioreactor were developed by Yang et al. (2016). ${ }^{19}$ Fluid velocity between light and dark areas increased from $\sim 0.9 \mathrm{~cm}$ $\mathrm{s}^{-1}$ to $\sim 3.5 \mathrm{~cm} \mathrm{~s}^{-1}$. Biomass yield increased by $70 \%$ with the enhanced flashing light effect. However, microalgal cells movement and L/D cycle in the new design remained unexplored due to the limitations of experimental measurement method.

In the present study, the movement of algal cells in the vortex flow field produced by horizontal baffles was analyzed through CFD. The cell L/D cycle period, fraction of time that the microalgal cell was exposed to light zone (light time fraction), and the horizontal fluid velocity were investigated at different gas aeration rates and microalgal concentrations. The results demonstrated that horizontal baffles can shorten the $\mathrm{L} / \mathrm{D}$ cycle period of the microalgal cells and thereby improving the microalgal growth rate in flat panel bioreactor.

\section{Materials and methods}

\subsection{Geometries of the flat-panel reactor and horizontal baffles}

Panel bioreactor (PBR) schematic with horizontal baffles was showed in Fig. 1. It is $20 \mathrm{~cm}$ long, $16 \mathrm{~cm}$ wide, and $90 \mathrm{~cm}$ high. The diameters of the horizontal baffles are $7 \mathrm{~cm}$ with the length of $20 \mathrm{~cm}$. The axis of the lowest horizontal tube is placed $8 \mathrm{~cm}$ from the left wall and $9 \mathrm{~cm}$ above the bottom of the PBR. Five more horizontal baffles have the same $x$-axis coordinates and the same axis distance of $12 \mathrm{~cm}$ on the $y$-axis direction.

\subsection{Flow simulation in the flat-panel reactor}

The PBR was 3D meshed using ANSYS ICEM CFD 15.0 (64 bit), and the simulation was conducted with ANSYS FLUENT 15.0 (64 bit). The Eulerian two-phase model was applied because using the multiphase model is unavoidable while bubbles occur in the photobioreactors. A standard $k$ - $\varepsilon$ model was chosen with first-order exactness to describe the turbulent flow behavior inside the PBRs. In this model, turbulent dispersion force and gas-liquid interphase drag force were considered. The outer walls and the internal structures of the PBRs were set as no-slip boundary conditions to water. The outlet was set as degassing boundary, representing that only the gas in the dispersed phase could escape from the surface and the continuous phase could not go through the top surface. ${ }^{18}$ The time step for the transient flow field computation was set as $0.004 \mathrm{~s}$. To confirm grid independency, three scale grids (532 525; 904944 ; and 1174084 ) were used. Small difference was found between the computed values of and 1174084 cells. So, the mesh with 904944 cells was adopted for all the cases.

\subsection{Fluid velocity and $\mathrm{L} / \mathrm{D}$ cycle period calculation}

Fluid velocity and L/D cycle period were calculated according to the result of simulation. The vertical fluid velocity $\left(V_{z}\right)$ was calculated with the velocity of two lines on the $z$-axis direction $\left(V_{z_{1}}\right.$ and $\left.V_{z_{2}}\right)$. Line 1 was from point $(X=-70 \mathrm{~mm}, Y=0 \mathrm{~mm}, Z=$ $100 \mathrm{~mm}$ ) to point $(X=-70 \mathrm{~mm}, Y=0 \mathrm{~mm}, Z=700 \mathrm{~mm})$, and line 2 was from point $(X=70 \mathrm{~mm}, Y=0 \mathrm{~mm}, Z=100 \mathrm{~mm})$ to point $(X=70 \mathrm{~mm}, Y=0 \mathrm{~mm}, Z=700 \mathrm{~mm})$. Thus, $V_{z}=\left(V_{Z_{1}}+\right.$ $\left.V_{Z_{2}}\right) / 2$. The horizontal fluid velocity $\left(V_{x}\right)$ was calculated with the velocity of five lines on the $x$-axis direction. Line $i(i=1,2,3$, $4,5)$ was from point $(X=-80 \mathrm{~mm}, Y=0 \mathrm{~mm}, Z=15 \mathrm{~mm}+$ $120 \times i \mathrm{~mm})$ to point $(X=-80 \mathrm{~mm}, Y=0 \mathrm{~mm}, Z=15 \mathrm{~mm}+$ $120 \times i \mathrm{~mm})$. Thus, $V_{x}=1 / 5 \sum_{i=1}^{5} V_{x i}$. The bottom of the PBR was set as $(0,0,0)$, as described in Fig. 1a. A total of 1000 simulated particles were injected from two entrance ports; the two coordinates of the ports were $(60 \mathrm{~mm}, 0 \mathrm{~mm}, 10 \mathrm{~mm})$ and $(-60 \mathrm{~mm}$, $0 \mathrm{~mm}, 700 \mathrm{~mm}$ ). The particle diameter used for the algal cells was $5 \mu \mathrm{m}$ with a density of $1000 \mathrm{~kg} \mathrm{~m}^{-3}$. The maximum particle tracking time was set to $60 \mathrm{~s}$. Discrete random walk model, ${ }^{20}$ drag force $\left(\frac{1}{8} \pi \rho d^{2} C_{\mathrm{D}}\left|\overrightarrow{v_{\mathrm{f}}}-\overrightarrow{v_{\mathrm{p}}}\right|\left(\overrightarrow{v_{\mathrm{f}}}-\overrightarrow{v_{\mathrm{p}}}\right)\right)$, and pressure gradient force $\left(\frac{\pi d^{3} \rho_{\mathrm{f}}}{6} \frac{\mathrm{d} \overrightarrow{v_{\mathrm{f}}}}{\mathrm{d} t}\right)^{21}$ were considered during the simulation, where $d$ is the particle diameter, $\rho$ is its density, and $\vec{\nu}$ is the velocity vector, with the subscripts $\mathrm{p}$ stands for particle and for the fluid (the continuous phase).

The spatial position of each spherical particle was recorded every $0.1 \mathrm{~s}$. The L/D cycle period $\left(T_{\mathrm{av}}{ }^{i}\right)$ of a microalgae cell was defined and calculated following the method described by Huang et al. ${ }^{22}$ The average L/D cycle period ${ }^{10}$ of each cell was used to calculate the average $\mathrm{L} / \mathrm{D}$ cycle period of the entire population $\left(T_{\mathrm{av}}^{\mathrm{p}}\right) \cdot T_{\mathrm{av}}^{\mathrm{p}}=\lim _{N \rightarrow \infty}\left(1 / N \sum_{i=1}^{N} T_{\mathrm{av}}{ }^{i}\right)$, where $N$ is the number of the cells. Flashing light frequency $(f)$ and light time fraction were defined as $f=1 / T_{\mathrm{av}}^{i}$ and $\varphi=\left(1 / n \sum_{i}^{n} t_{1}\right) / T_{\mathrm{av}}{ }^{i}$, respectively. All the parameters above were processed by MATLAB R2012b (64 bit) and Microsoft Office Excel.

\subsection{Determination of critical depth between light and dark zone under various microalgal concentrations}

A glass cylinder (diameter $=10 \mathrm{~cm}$ ) was filled to different depths with the microalgal solution. A photosensitive electrode (GLZ-C, Zhejiang Top Instrument Co., Ltd. China) was installed on the bottom of the cylinder to record light intensity, and illumination intensity $(I)$ detected by photosensitive electrode was recorded as fluid depths increasing in $1 \mathrm{~cm}$ increments. $I_{0}$, which was the illumination intensity without microalgal solution, was recorded as $530 \mu \mathrm{mol} \mathrm{m}{ }^{-2} \mathrm{~s}^{-1}$. In this study, the critical $I$ of Chlorella was set as $96.84 \mu \mathrm{mol} \mathrm{m}{ }^{-2} \mathrm{~s}^{-1}$ according to the report, ${ }^{23}$ and the depth 


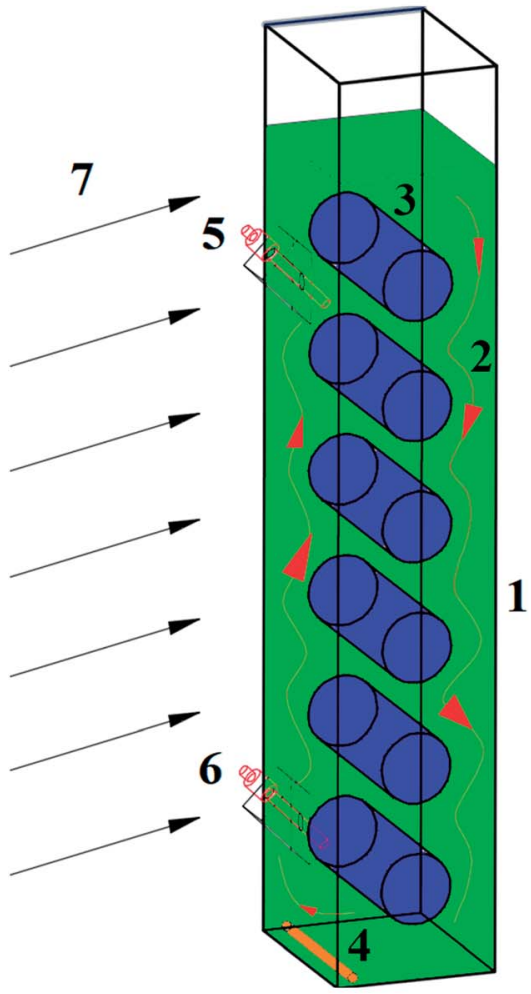

(a)

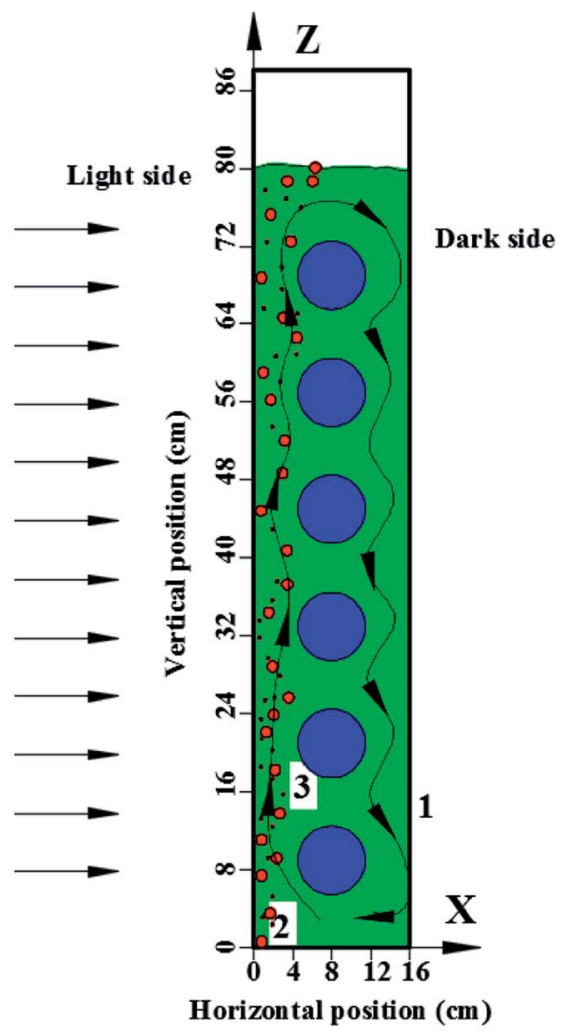

(b)

Fig. 1 Schematic of a panel bioreactor with horizontal baffles. (a) Schematic of photobioreactor. (1) Panel bioreactor, (2) microalgae fluid with flow direction arrows, (3) horizontal baffles, (4) porous gas aerator, (5 and 6) two online precise pH probes or dissolved oxygen probes, (7) continuous artificial light, (b) side view of photobioreactor.

corresponding to this critical $I$ was defined as critical depth. In the PBR, the region where $I$ was lower than the critical $I$ or depth was bigger than the critical depth was defined as dark zone, and the remaining region was defined as light zone. Five concentrations of microalgal solution $\left(C_{i}=0.28,0.56,0.85,1.1,1.7 \mathrm{~g} \mathrm{~L}^{-1}\right)$ were tested. Microalgal biomass were centrifugation at $8000 \mathrm{rpm}$ for $5 \mathrm{~min}$ and then dried under $90{ }^{\circ} \mathrm{C}$ for $24 \mathrm{~h}$ to test microalgal concentrations by gram per liter.

\subsection{Experimental measurement}

Velocity magnitude was tested by using the miniature ultrasonic doppler velocimeter (Boyida Technology Co., Ltd., China) to validate the correctness of the simulation results for velocity. Solution-phase mixing time were calculated according to the method of Mendoza et al. (2013). ${ }^{24}$ Water was employed as test fluid during the measurement. Initially, the water $\mathrm{pH}$ was adjusted to $4.0 \pm 1$ by adding chlorhydric acid $(35 \%, w / v)$. Then, $0.20 \mathrm{ml} \mathrm{NaOH}$ solution $\left(12 \mathrm{~mol} \mathrm{~L}^{-1}\right)$ per liter of water was added as alkalinity tracer. The time was recorded when the alkalinity tracer was added. The mixing time is the required time for $\mathrm{pH}$ variations reaching to lower than $5 \%$ of the final stable value. The $\mathrm{pH}$ probes were used to measure the response to the $\mathrm{pH}$ pulse at two positions in this PBR. The overall volumetric masstransfer coefficient $K_{\mathrm{L}} a_{\mathrm{L}}$ was measured by the method of Sierra et al.(2008). ${ }^{25}$ Water in the PBR was alternately aerated with air and $\mathrm{N}_{2} . \mathrm{N}_{2}$ and air aeration rates were controlled by mass flow meter (SevenstarCS200, China). Then, mass-transfer coefficient was calculated according to the formula: $\mathrm{d} C_{\mathrm{L}} / \mathrm{d} t=k_{\mathrm{L}} a_{\mathrm{L}}\left(C^{*}-\right.$ $C_{\mathrm{L}}$ ), where $C^{*}$ was the saturation concentration of dissolved oxygen. Dissolved oxygen probes (Mettler Toledo, InPro6850i/ 12/120) and $\mathrm{pH}$ probes (Mettler Toledo, InPro3253i/SG/120) were connected to transmitters and data acquisition software (i-7017fc, ICP DAS, Taiwan). Every $0.1 \mathrm{~s}$, measurements were automatically recorded.

\subsection{Microalgal cultivation}

Microalgae mutant Chlorella PY-ZU1 was cultivated with Bristol's solution (also called soil extract, SE) and measured by the same method described by Cheng et al. (2013). ${ }^{26}$ Chlorella PY-ZU1 was cultivated in the flat-plate PBR under $23{ }^{\circ} \mathrm{C}$ with continuous illumination of $530 \mu \mathrm{mol} \mathrm{m} \mathrm{m}^{-2} \mathrm{~s}^{-1} .15 \% \mathrm{CO}_{2}$ was continuously aerated into the culture medium with $0.02 \mathrm{vvm}$ flow rate.

\section{Results and discussion}

\subsection{L/D cycle periods in the PBR with horizontal baffles}

Light transmission in microalgal solution is limited. Microalgal cells grow slowly in the deep position where light can not reach. Flashing light effect in microalgae cultivation field was regarded 
as periodic exposure of microalgae to light or rapid travel between dark and light zones. Flashing-light effect can be characterized by L/D cycle period. When microalgal concentration was $0.85 \mathrm{~g} \mathrm{~L}^{-1}$, the critical depth from light zone to dark zone was test to be $2 \mathrm{~cm}$. Fig. 2 showed the effects of gas aeration rate on light/dark cycle period in a PBR with or without horizontal baffles under a microalgal concentration of $0.85 \mathrm{~g} \mathrm{~L} \mathrm{~L}^{-1}$, which was analyzed according to the simulation result. While the air flow rate increased from $0.02 \mathrm{vvm}$ to $0.04 \mathrm{vvm}$, the L/D cycle period decreased from $14.1 \mathrm{~s}$ to $10.7 \mathrm{~s}$ with the horizontal baffles, and decreased from $17.1 \mathrm{~s}$ to $12.1 \mathrm{~s}$ without the horizontal baffles. The addition of horizontal baffles decreased the L/D cycle period by $17.4 \%$ under $0.02 \mathrm{vvm}$ air aeration rate. The flashing-light effect of the microalgae from dark area to light area was improved. Microalgal growth rate can be obviously improved with the enhanced flashing light effect. $^{27}$ Fig. 3b showed the vertical velocity and horizontal velocity of fluid in a PBR with or without horizontal baffles, which was obtained from the simulation result. As the aeration rate increased from $0.02 \mathrm{vvm}$ to $0.04 \mathrm{vvm}$, horizontal fluid velocity increased from $1.0 \mathrm{~cm} \mathrm{~s}^{-1}$ to $1.3 \mathrm{~cm} \mathrm{~s}^{-1}$ with the horizontal baffles, and increased from $0.52 \mathrm{~cm} \mathrm{~s}^{-1}$ to $0.62 \mathrm{~cm} \mathrm{~s}^{-1}$ without the horizontal baffles [Fig. 3a]. The velocity magnitudes in the PBRs with and without horizontal baffles were measured using a miniature ultrasonic Doppler velocimeter. When the aeration rate was $0.02 \mathrm{vvm}$, the test average velocity magnitudes were $0.95 \mathrm{~cm} \mathrm{~s}^{-1}$ with horizontal baffles and $0.48 \mathrm{~cm} \mathrm{~s}^{-1}$ without horizontal baffles, and the differences from the simulation results were $5 \%$ and $7.7 \%$, respectively. This result demonstrated that the simulation result was acceptable.

With the horizontal baffles, small scale vortex flow was developed in the PBR, around one horizontal tube baffle, or between two baffles. In the presence of horizontal baffles under air aeration rate of $0.02 \mathrm{vvm}$, the horizontal fluid velocity significantly increased by 1.8 times especially in the middle of the PBR. Thus, culture fluid can be quickly moved from dark area to light area. Only a large vortex flow was generated within PBR without horizontal baffles. Then, fluid flow direction mainly changed at the bottom and top of the PBR. ${ }^{28}$ The major part of the microalgal culture fluid cannot move quickly to the other side in the central section of the PBR. Several studies reported that flashing light effect of the microalgae from dark area to light area can enhance photosynthesis and improve the quality and quantity of microalgal biomass. For that reason, it is significant to consider the integration of flashing light effect into microalgal cultivation systems. ${ }^{17}$

The vertical fluid velocity increased from $9.6 \mathrm{~cm} \mathrm{~s}^{-1}$ to $10.4 \mathrm{~cm} \mathrm{~s}^{-1}$ and from $10.2 \mathrm{~cm} \mathrm{~s}^{-1}$ to $13.9 \mathrm{~cm} \mathrm{~s}^{-1}$ as the gas aeration rate increased from $0.02 \mathrm{vvm}$ to $0.04 \mathrm{vvm}$ with and without the horizontal baffles. Vertical fluid velocity decreased by $25 \%$ when the horizontal baffles were used under $0.04 \mathrm{vvm}$ air aeration. Longer bubble residence time can be achieved with a slower vertical fluid velocity. The $\mathrm{CO}_{2}$ utilization efficiency was improved as more $\mathrm{CO}_{2}$ was dissolved into the culture fluid.

Fluid movement was obviously affected by horizontal baffles, especially in the upper section of the PBR [Fig. 3b] as parts of air bubbles were blocked by the horizontal baffles. The vertical fluid velocity was not increased further as aeration rate increased from $0.06 \mathrm{vvm}$ to $0.1 \mathrm{vvm}$ with the horizontal baffles. So the $\mathrm{L} / \mathrm{D}$ cycle period was not decreased further. Vertical and horizontal fluid velocities increased from $16.5 \mathrm{~cm} \mathrm{~s}^{-1}$ to $20.1 \mathrm{~cm} \mathrm{~s}^{-1}$ and from $0.7 \mathrm{~cm} \mathrm{~s}^{-1}$ to $0.9 \mathrm{~cm} \mathrm{~s}^{-1}$, respectively, while gas aeration rate increased from $0.06 \mathrm{vvm}$ to $0.1 \mathrm{vvm}$ without horizontal baffles. A high intensity turbulent region was developed within the reactor. Hence, the L/D cycle period decreased from $9.6 \mathrm{~s}$ to $8.2 \mathrm{~s}$ while gas flow rate increased from $0.06 \mathrm{vvm}$ to $0.1 \mathrm{vvm}$.

Light zone was only $2 \mathrm{~cm}$ depth from the light direction with a microalgal concentration of $0.85 \mathrm{~g} \mathrm{~L}^{-1}$. So light time of algal cell was decreased with the increased vertical fluid velocity

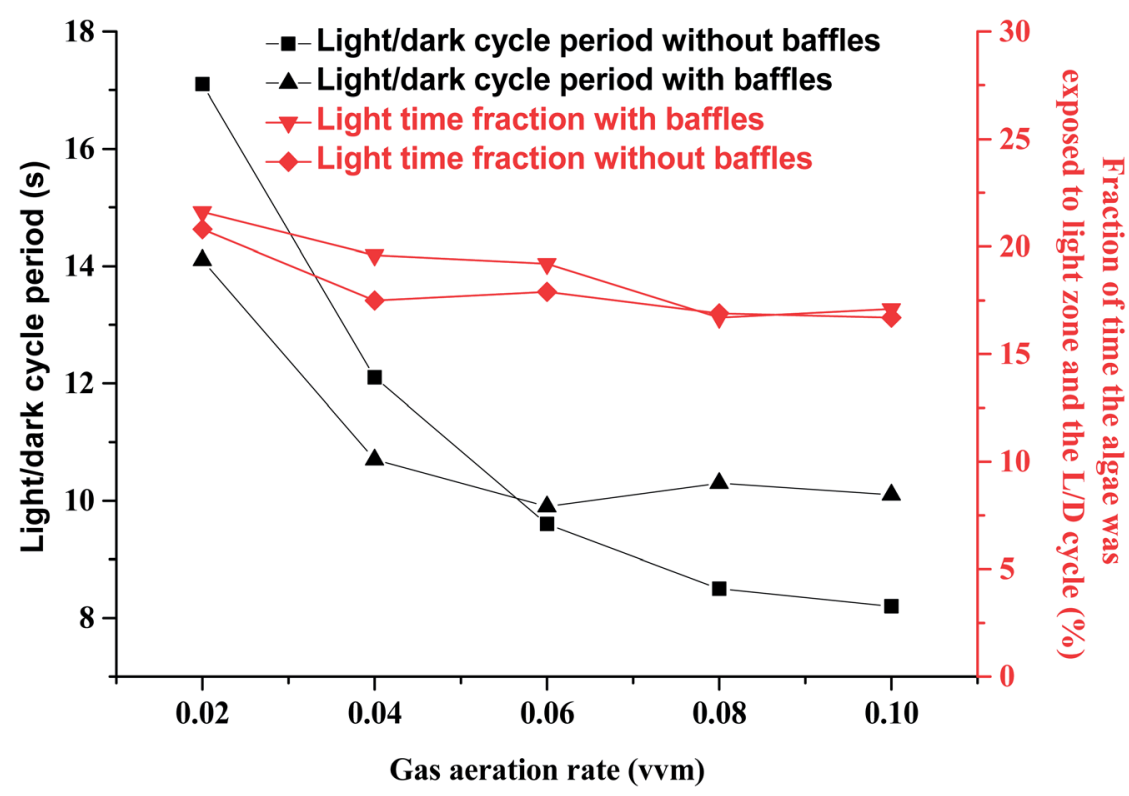

Fig. 2 Effects of gas aeration rate on light/dark cycle period in a panel bioreactor with horizontal baffles. 


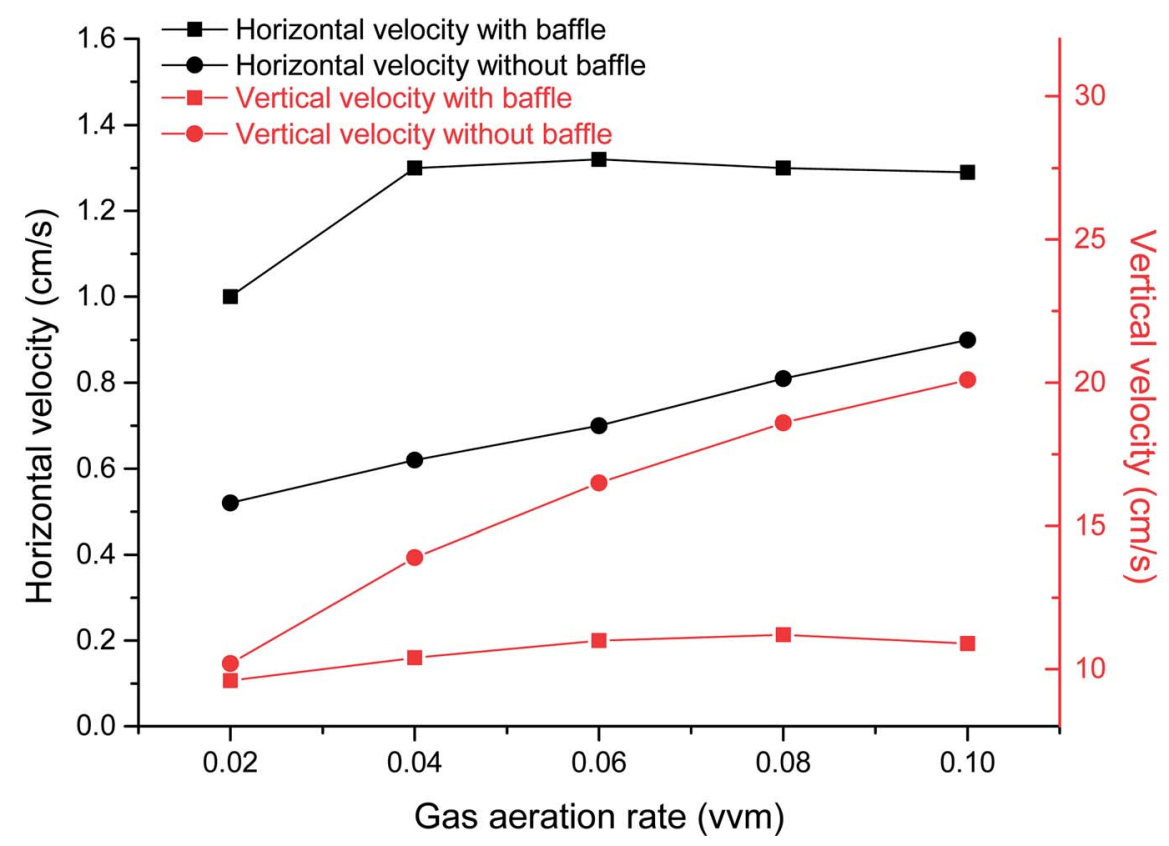

(a)

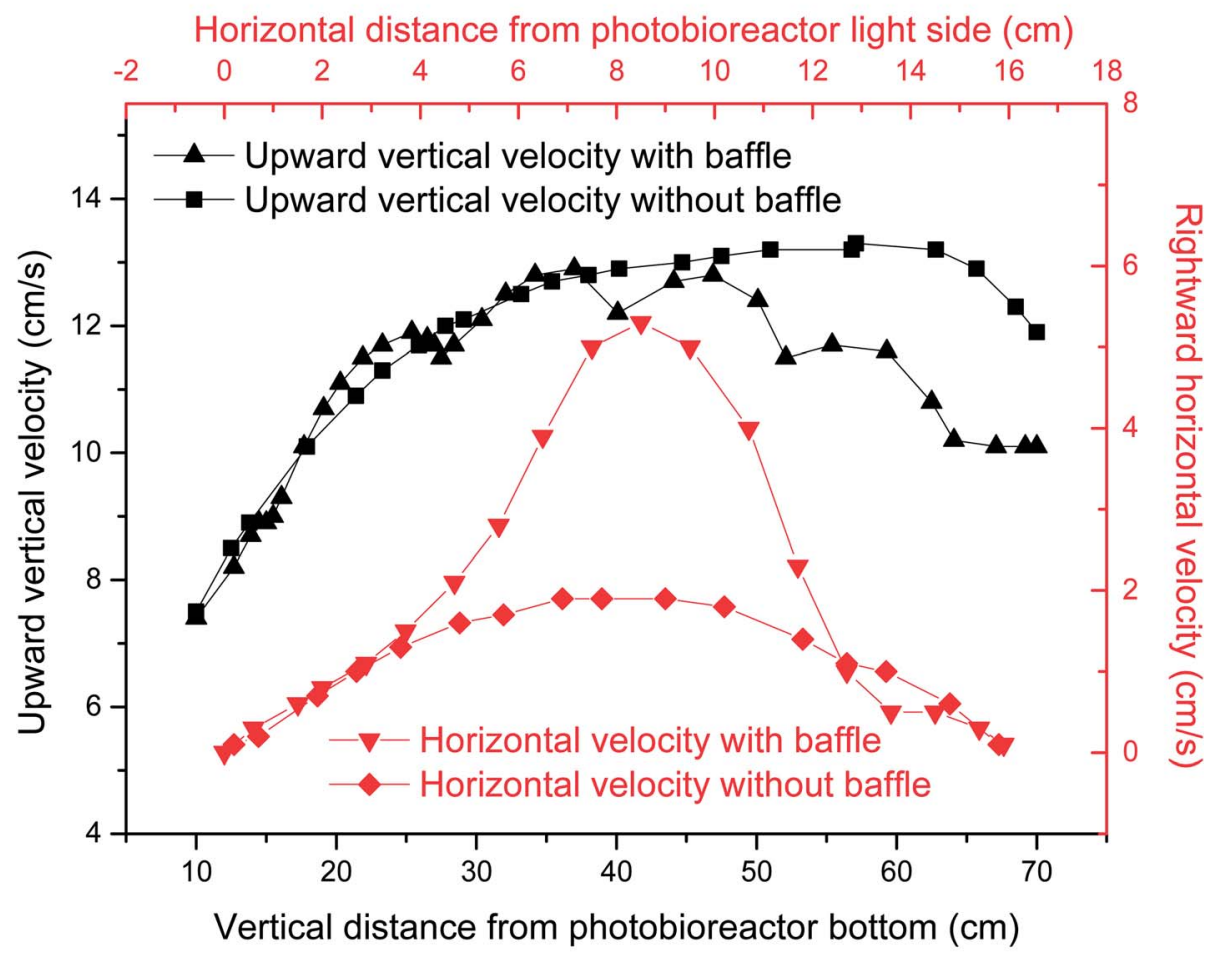

(b)

Fig. 3 Vertical velocity and horizontal velocity of fluid in a panel bioreactor with horizontal baffles. (a) Vertical velocity and horizontal velocity under different gas aeration rate (b) vertical velocity and horizontal velocity at different position in a panel bioreactor under gas aeration rate of $0.02 \mathrm{vvm}$.

while gas aeration rate was increased from $0.02 \mathrm{vvm}$ to $0.1 \mathrm{vvm}$. Thus, the light time fraction slightly decreased from $\sim 21 \%$ to $\sim 17 \%$ (Fig. 2). Flue-gas (especially from a coal-fired power plant) aeration rate is restricted because it contains $\mathrm{NO}_{x}$ and $\mathrm{SO}_{x},{ }^{29}$ high flashing light frequency can be obtained with horizontal baffles at a low gas aeration rate. 


\subsection{L/D cycle periods under different microalgal concentration}

The L/D cycle period time was calculated based on different microalgal concentrations under $0.02 \mathrm{vvm}$ gas aeration rate. The critical depth was decreased from $5 \mathrm{~cm}$ to $1 \mathrm{~cm}$ when the microalgal concentration was increased from $0.28 \mathrm{~g} \mathrm{~L}^{-1}$ to $1.7 \mathrm{~g} \mathrm{~L}^{-1}$. L/D cycle period decreased from $15.6 \mathrm{~s}$ to $11.4 \mathrm{~s}$ and the light time fraction decreased from $39 \%$ to $17 \%$ when the microalgal concentration was increased from $0.28 \mathrm{~g} \mathrm{~L}^{-1}$ to $1.7 \mathrm{~g} \mathrm{~L}^{-1}$ in the presence of horizontal baffles (Fig. 4). The crosssectional flow area was periodically changed when horizontal baffles were used. Air was aerated close to right side of the wall (Fig. 1b). Small scale vortex flow was developed in the plate reactor, around one horizontal tube baffle, or between two of the horizontal baffles. Fluid fluctuations increased when the critical depth line moved to the right side of the wall. Thus, the L/D cycle period decreased by $27 \%$ as the critical depth was decreased from $5 \mathrm{~cm}$ to $1 \mathrm{~cm}$.

The $\mathrm{L} / \mathrm{D}$ cycle period was $\sim 17 \mathrm{~s}$ and light time fraction decreased from $35 \%$ to $22 \%$ when the microalgal concentration was increased from $0.28 \mathrm{~g} \mathrm{~L}^{-1}$ to $1.7 \mathrm{~g} \mathrm{~L}^{-1}$ in the absence of horizontal baffles (Fig. 4). Flow direction of fluid mostly changed at the bottom and top of the PBR. Most of the microalgae fluid can not move quickly from dark area to light area in center section of the PBR. Movement of particles inside the PBR was relatively uniform; thus, the $\mathrm{L} / \mathrm{D}$ cycle period time was not shortened with the increase of microalgal concentration.

The L/D cycle period, which was based on different microalgal concentrations, was the same at different fluid depths. The dark area comprises roughly $90 \%$ of the cycle when the microalgal concentration was $1.1 \mathrm{~g} \mathrm{~L}^{-1}$. Microalgal cells cannot timely move from one side to the other side in the PBR without horizontal baffles (Fig. 5a). Small light dark cycle period was good for cells growth. Most L/D cycle periods were longer than $5 \mathrm{~s}$, and the probability of the L/D cycle period with 5-10 s was $27.9 \%$ (Fig. 5b). The fluid flow direction was changed quickly, vortex flow fields were produced, and the vertical fluid velocity increased from $0.52 \mathrm{~cm} \mathrm{~s}^{-1}$ to $1.0 \mathrm{~cm} \mathrm{~s}^{-1}$ when the horizontal baffles were used. Consequently, the cell was quickly moved from dark area to light area in the PBR (Fig. 5a). The probability of the L/D cycle period with $0-5 \mathrm{~s}$ increased from $1 \%$ to $5.9 \%$, and the probability of the L/D cycle period with 5-10 s increased from $27.9 \%$ to $43.6 \%$ (Fig. $5 \mathrm{~b}$ ), indicating an increase of $56 \%$ when the horizontal baffles were used. The result showed that the cells has a bigger probability to gain a small light dark cycle period in PBR with horizontal baffles than that in PBR with baffles.

\subsection{Solution mixing and mass transfer in the PBR with horizontal baffles}

Effects of gas aeration rate on mass transfer coefficient and mixing time in PBR with or without the horizontal baffles were tested by experiment [Fig. 6a]. When the gas aeration rate was increased from $0.02 \mathrm{vvm}$ to $0.1 \mathrm{vvm}$, mass-transfer coefficient decreased from $48.1 \mathrm{~s}$ to $27.6 \mathrm{~s}$ without the horizontal baffles, and decreased from $39.6 \mathrm{~s}$ to $22.5 \mathrm{~s}$ with the horizontal baffles. When the horizontal baffles existed, mixing time decreased by $13 \%$ under 0.06 vvm gas aeration rate. The PBR mixing efficiency improved (bigger horizontal velocity) while horizontal baffles were used. Appropriate mixing condition allowed even nutrient distribution in the culture medium and accelerated microalgal growth. ${ }^{30}$

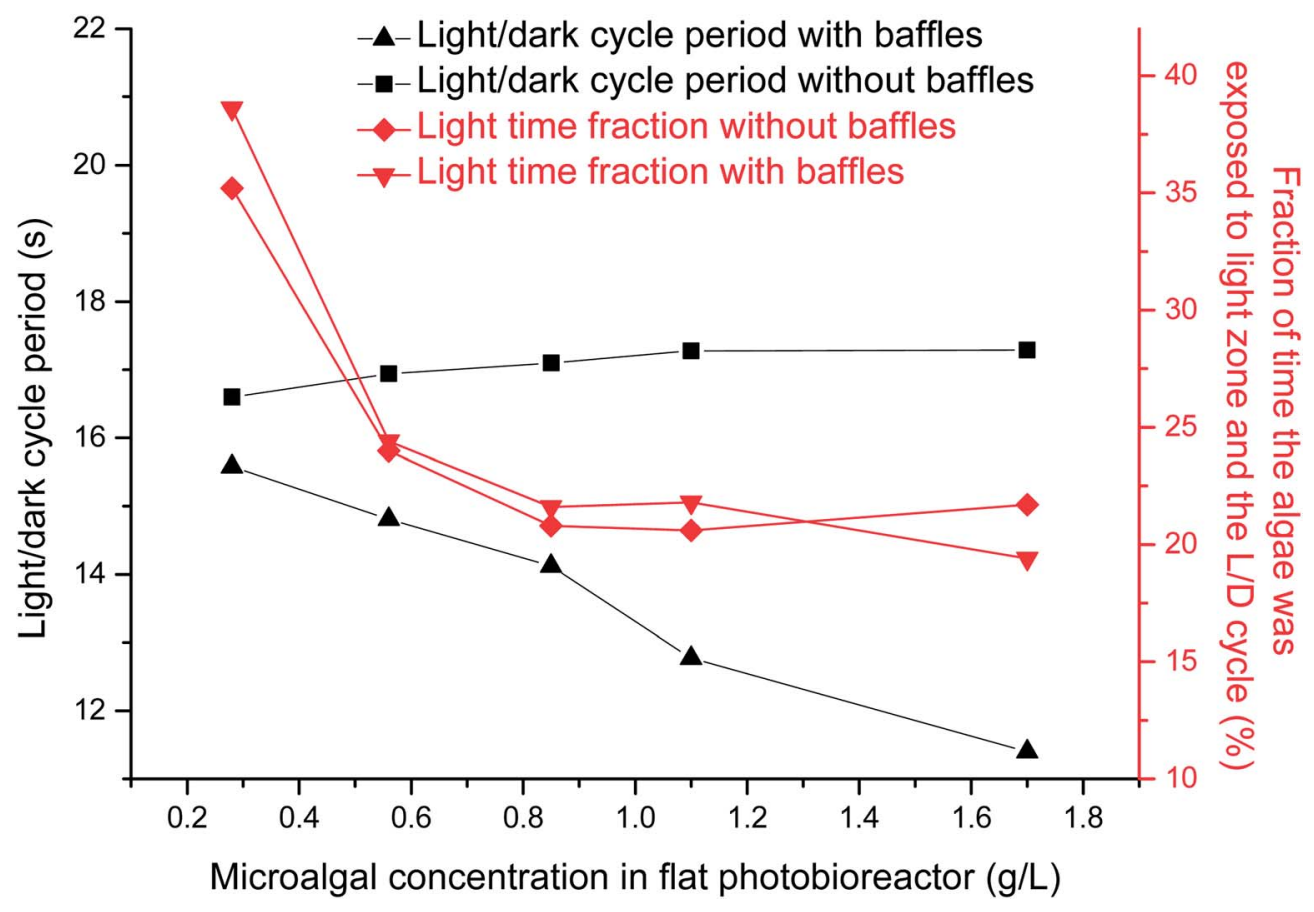

Fig. 4 Effects of microalgal concentration on light/dark cycle period in a panel bioreactor with horizontal baffles. 


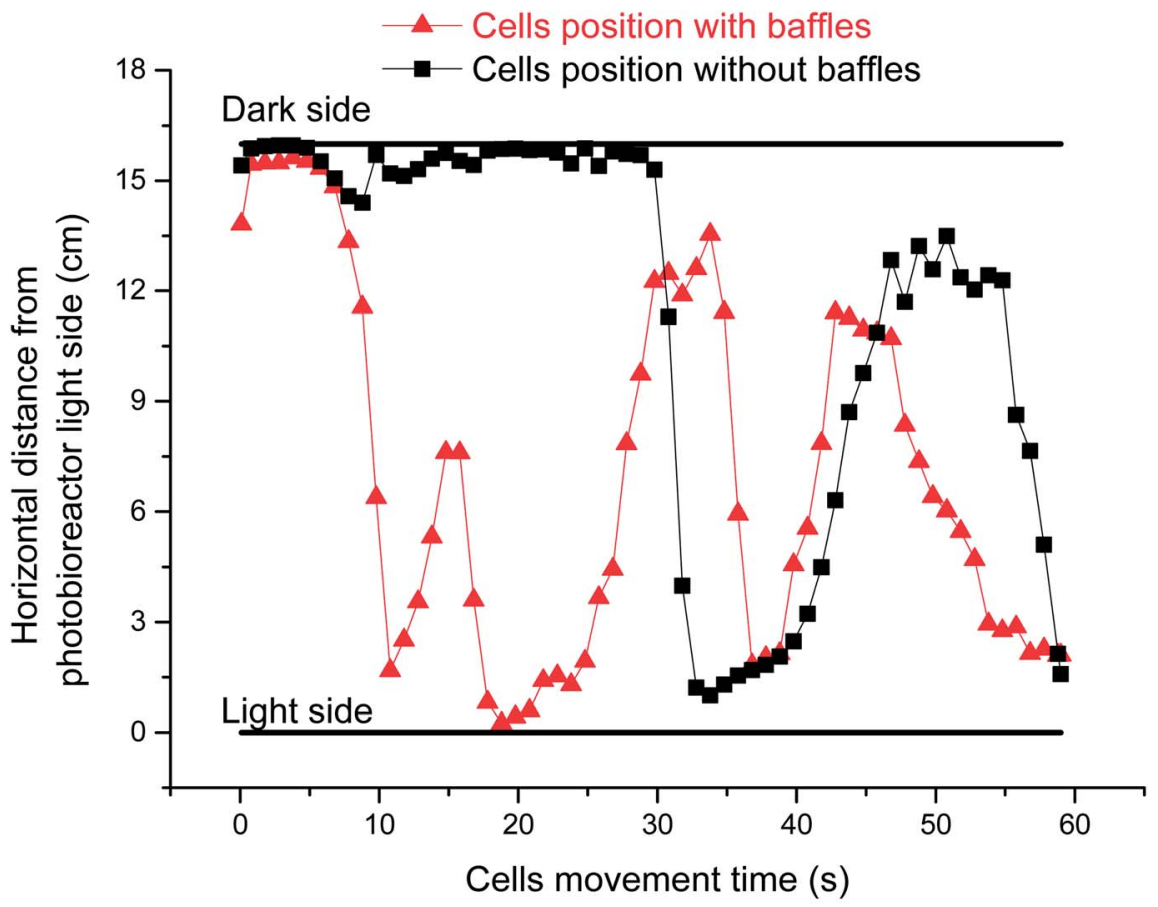

(a)

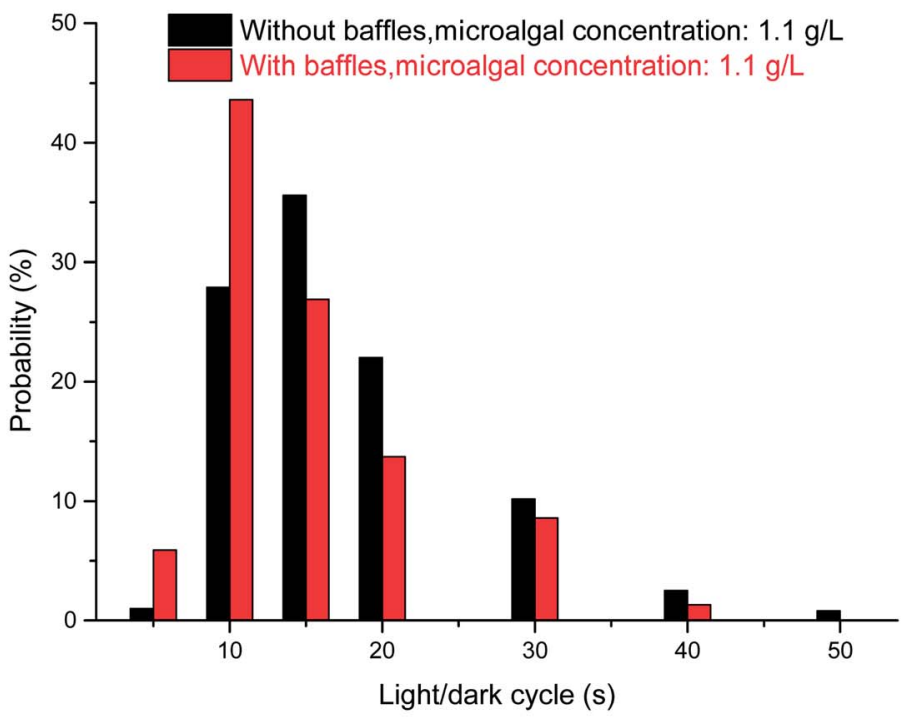

(b)

Fig. 5 Effects of horizontal baffles on cell flow trajectory in a panel bioreactor. (a) Cells flow trajectory between light side and dark side; (b) probability of light/dark cycle period.

When air aeration rate was increased from $0.02 \mathrm{vvm}$ to $0.1 \mathrm{vvm}$, mass-transfer coefficient increased from $0.053 \mathrm{~h}^{-1}$ to $0.142 \mathrm{~h}^{-1}$ without the horizontal baffles, and increased from $0.081 \mathrm{~h}^{-1}$ to $0.208 \mathrm{~h}^{-1}$ with the horizontal baffles. The residence time of rising bubbles was higher in the culture solution because that solution vertical velocity decreased by $18 \%$ under $0.06 \mathrm{vvm}$ gas aeration rate. Therefore, mass transfer coefficient increased by $31 \%$ under $0.06 \mathrm{vvm}$ gas aeration rate, thus leading to higher mass transfer and accelerated $\mathrm{CO}_{2}$ dissolution. ${ }^{31,32}$

\subsection{Increased microalgal biomass yield in the presence of horizontal baffles}

Effects of horizontal baffles on microalgal growth rate and $\mathrm{pH}$ values versus time with $15 \% \mathrm{CO}_{2}$ under a aeration rate of 0.02 vvm were illustrated in Fig. $6 \mathrm{~b}$. The $\mathrm{pH}$ of SE culture decreased quickly from 6.8 to 5.8 during the first $4 \mathrm{~h}$ because $\mathrm{CO}_{2}$ quickly dissolved into the medium. The culture $\mathrm{pH}$ increased slowly after $4 \mathrm{~h}$, this increasing tendency of $\mathrm{pH}$ owing to the $\mathrm{CO}_{2}$ uptake by microalgae. The fluid flow direction was changed 


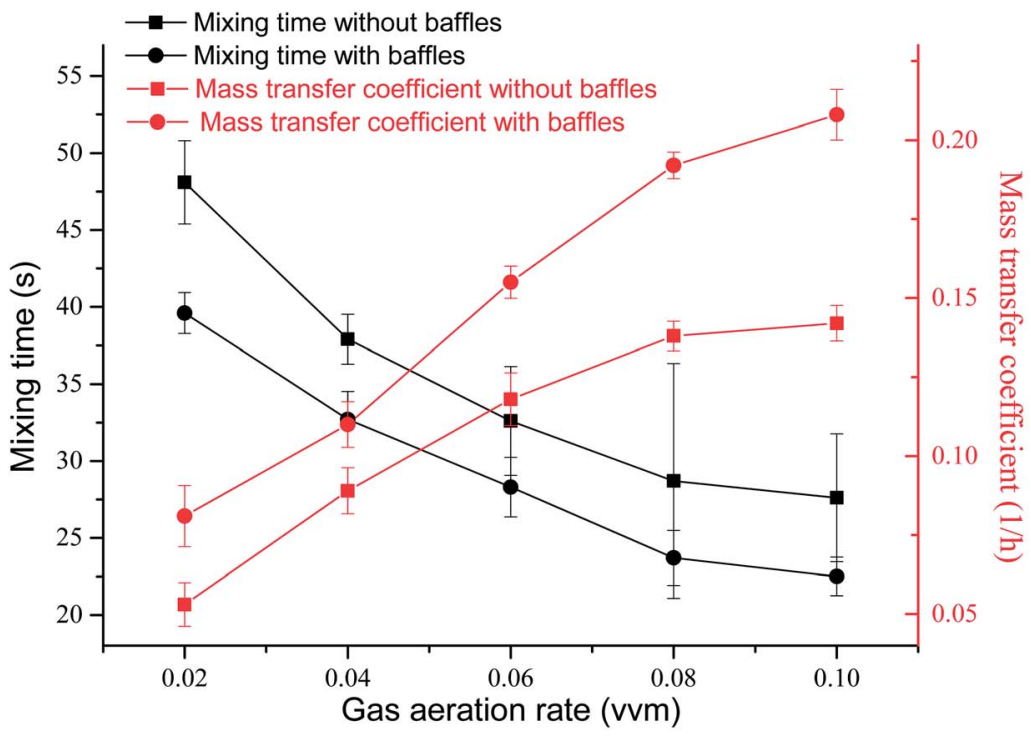

(a)

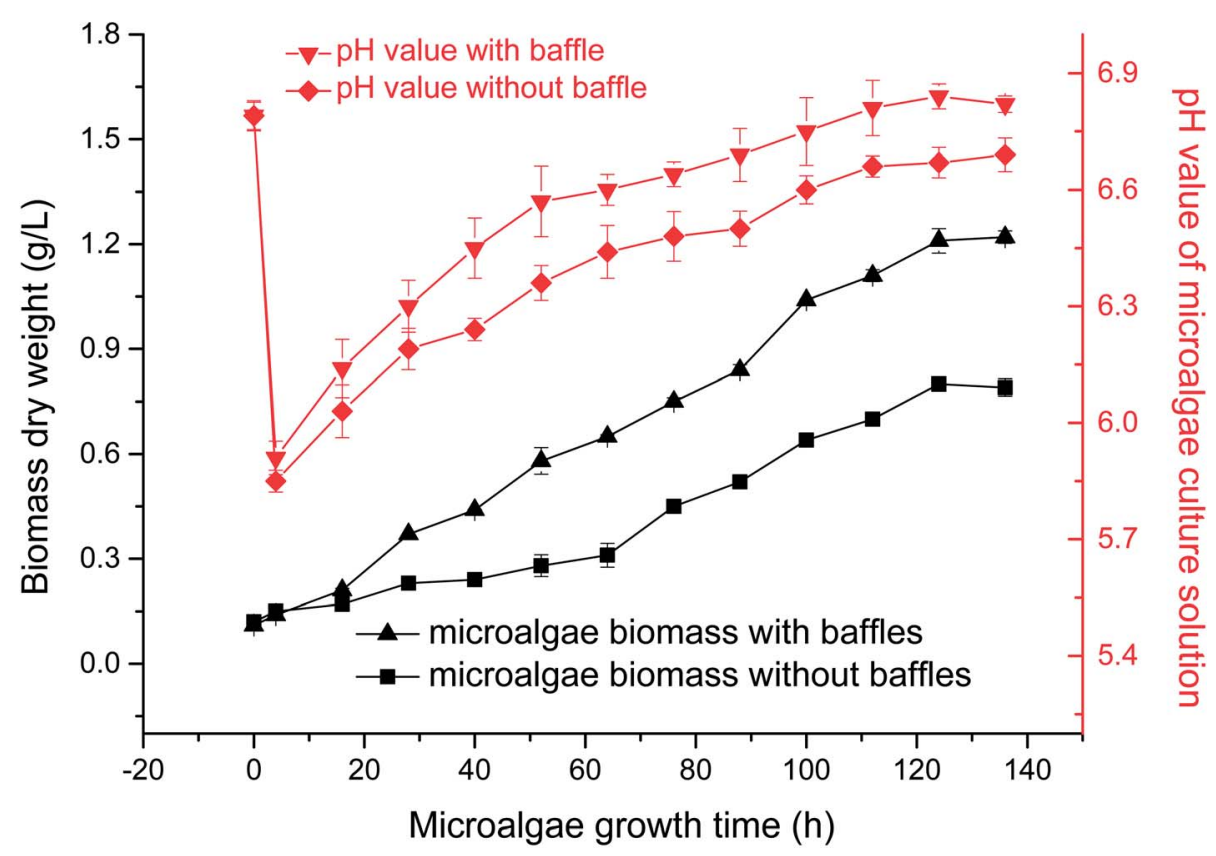

(b)

Fig. 6 Microalgal growth in an optimized flow field of a panel bioreactor with horizontal baffles. (a) Effects of gas aeration rate on mixing time and mass transfer; (b) effects of horizontal baffles on $\mathrm{pH}$ and microalgal growth.

quickly, vortex flow fields were produced, and the vertical fluid velocity increased from $0.52 \mathrm{~cm} \mathrm{~s}^{-1}$ to $1.0 \mathrm{~cm} \mathrm{~s}^{-1}$ when the horizontal baffles were used.

Consequently, the cell was quickly moved from dark area to light area in the PBR (Fig. 5a). The probability of the L/D cycle period with $5-10 \mathrm{~s}$ increased by $56 \%$ from $27.9 \%$ to $43.6 \%$ when the horizontal baffles were used. So the $\mathrm{L} / \mathrm{D}$ cycle period decreased by $17.4 \%$ under an air aeration rate of $0.02 \mathrm{vvm}$ when horizontal baffles were added. It is proposed that mixing has two separate but synergistic effects, for example, it not only moves the microalgal cells through a L/D cycle, but also decreases the boundary layer, which increases the rate of exchange through the cell wall of nutrients and metabolites. Thus, more nutrients can be uptake and light can be utilized more efficiently, so the biomass yield is increased. ${ }^{33}$ The biomass yield in the fifth day increased by roughly $51 \%$ in comparison with the condition without baffles at a same aeration rate. 


\section{Conclusion}

Hydrodynamic and flashing effect of a panel bioreactor with horizontal baffles were investigated by CFD simulation. The L/D cycle period decreased by $17.5 \%$ and the probability of the $\mathrm{L} / \mathrm{D}$ cycle period within 5-10 s increased by $56 \%$ when horizontal baffles were used under $0.02 \mathrm{vvm}$ gas aeration rate. Experiments confirmed the enhanced flow field in the bioreactor. Mixing time decreased by $13 \%$ and mass-transfer coefficient increased by $31 \%$ under $0.06 \mathrm{vvm}$ gas aeration rate. The microalgal biomass yield increased by $51 \%$ with the same light intensity. The optimized width of the PBR under different light intensities can be further investigated to increase the microalgal biomass yield per unit area.

\section{Conflicts of interest}

There are no conflicts to declare.

\section{Acknowledgements}

This study was supported by the National Key Research and Development Program - China (2016YFB0601003), National Natural Science Foundation - China (51476141).

\section{References}

1 S. Chiu, C. Kao, T. Huang, C. Lin, S. Ong, C. Chen, J. Chang and C. Lin, Bioresour. Technol., 2011, 102, 9135-9142.

2 V. Ashokkumar, E. Agila, P. Sivakumar, Z. Salam, R. Rengasamy and F. N. Ani, Energy Convers. Manage., 2014, 88, 936-946.

3 F. Han, H. Pei, W. Hu, M. Song, G. Ma and R. Pei, Energy Convers. Manage., 2015, 90, 315-322.

4 A. Saeid and K. Chojnacka, Chem. Eng. Res. Des., 2015, 93, 377-391.

5 Z. Yang, M. Del Ninno, Z. Wen and H. Hu, J. Appl. Phycol., 2014, 26, 2097-2107.

6 J. U. Grobbelaar, J. Appl. Phycol., 1994, 6, 331-335.

7 J. U. Grobbelaar, Bioresour. Technol., 1991, 38, 189-194.

8 J. U. Grobbelaar, B. Kroon, T. Burgerwiersma and L. R. Mur, Hydrobiologia, 1992, 238, 53-62.

9 J. U. Grobbelaar, L. Nedbal and V. Tichy, J. Appl. Phycol., 1996, 8, 335-343.

10 Z. Yang, J. Cheng, Q. Ye, J. Liu, J. Zhou and K. Cen, Bioresour. Technol., 2016, 220, 352-359.

11 R. Bannari, A. Bannari, B. Selma and P. Proulx, Chem. Eng. Sci., 2011, 66, 2057-2067.
12 J. P. Bitog, I. B. Lee, C. G. Lee, K. S. Kim, H. S. Hwang, S. W. Hong, I. H. Seo, K. S. Kwon and E. Mostafa, Comput Electron Agric, 2011, 76, 131-147.

13 A. Soman and Y. Shastri, Appl. Energy, 2015, 140, 246-255.

14 N. C. Kommareddy and V. V. Ananthula, J. Hazard., Toxic Radioact. Waste, 2017, 21, UNSP 04017012.

15 A. Massart, A. Mirisola, D. Lupant, D. Thomas and A. Hantson, Algal Res., 2014, 6, 210-217.

16 Q. Ye, J. Cheng, W. Guo, J. Xu, K. Li and J. Zhou, Bioresour. Technol., 2018, 255, 156-162.

17 Z. Chen, Z. Jiang, X. Zhang and J. Zhang, Biochem. Eng. J., 2016, 106, 129-138.

18 J. Huang, F. Feng, M. Wan, J. Ying, Y. Li, X. Qu, R. Pan, G. Shen and W. Li, Bioresour. Technol., 2015, 182, 151-159.

19 Z. Yang, J. Cheng, X. Xu, J. Zhou and K. Cen, Bioresour. Technol., 2016, 211, 519-526.

20 I. Perner-Nochta and C. Posten, J. Biotechnol., 2007, 131, 276285.

21 H. Luo and M. H. Al-Dahhan, Chem. Eng. Sci., 2011, 66, 907923.

22 J. Huang, S. Kang, M. Wan, Y. Li, X. Qu, F. Feng, J. Wang, W. Wang, G. Shen and W. Li, J. Appl. Phycol., 2015, 27, 49-58.

23 C. Sorokin and R. W. Krauss, Plant Physiol., 1958, 33, 109113.

24 J. L. Mendoza, M. R. Granados, I. de Godos, F. G. Acien, E. Molina, C. Banks and S. Heaven, Biomass Bioenergy, 2013, 54, 267-275.

25 E. Sierra, F. G. Acien, J. M. Fernandez, J. L. Garcia, C. Gonzalez and E. Molina, Chem. Eng. J., 2008, 138, 136-147.

26 J. Cheng, Y. Huang, J. Feng, J. Sun, J. Zhou and K. Cen, Bioresour. Technol., 2013, 136, 496-501.

27 N. Seyed Hosseini, H. Shang, G. M. Ross and J. A. Scott, Bioresour. Technol., 2015, 192, 432-440.

28 R. Reyna-Velarde, E. Cristiani-Urbina, D. Jazmin HernandezMelchor, F. Thalasso and R. Olivia Canizares-Villanueva, Chem. Eng. Process., 2010, 49, 97-103.

29 J. Cheng, Z. Yang, Y. Huang, L. Huang, L. Hu, D. Xu, J. Zhou and K. Cen, Bioresour. Technol., 2015, 190, 235-241.

30 C. Chen, K. Yeh, R. Aisyah, D. Lee and J. Chang, Bioresour. Technol., 2011, 102, 71-81.

31 M. Knezevic and D. Povrenovic, Chem. Eng. Sci., 2015, 134, 129-137.

32 S. Zhao, Y. Ding, Q. Liao, X. Zhu and Y. Huang, RSC Adv., 2015, 5, 32615-32625.

33 J. U. Grobbelaar, J. Appl. Phycol., 1989, 1, 333-340. 